\author{
A. Boehler*, M. Estenne
}

Post-transplant bronchiolitis obliterans. A. Boehler, M. Estenne. (C)ERS Journals Ltd 2003.

ABSTRACT: Over the last decade, improvements in surgical techniques, lung preservation, immunosuppression, and management of ischaemia/reperfusion injury and infections have made intermediate-term survival after lung transplantation an achievable goal. However, chronic allograft dysfunction in the form of bronchiolitis obliterans remains a major hurdle that threatens both the quality of life and long-term survival of the recipients. It affects up to $50-60 \%$ of patients who survive 5 yrs after surgery, and it accounts for $>\mathbf{3 0} \%$ of all deaths occurring after the third postoperative year.

This article discusses the alloimmune-dependent and -independent risk factors for bronchiolitis obliterans, the current understanding of the pathogenesis of bronchiolitis obliterans based on results of animal and human studies, the clinical staging of the complication, strategies that may contribute to the prevention and/or early detection of bronchiolitis obliterans, and suggestions for future research.

Eur Respir J 2003; 22: 1007-1018.
*Division of Pulmonary Medicine, University Hospital, Zurich, Switzerland. ${ }^{\#}$ The Chest Service, Erasme University Hospital, Brussels, Belgium.

Correspondence: M. Estenne, Chest Service, Erasme University Hospital, 808, Route de Lennik, B-1070 Brussels, Belgium.

Keywords: Bronchiolitis obliterans, chronic allograft dysfunction, chronic rejection, lung transplantation

Received: April 82003

Accepted: April 92003

A. Boehler holds a Swiss National Science Foundation Professorship position.
Over the last decade, improvements in surgical techniques, lung preservation, immunosuppression, and management of ischaemia/reperfusion injury and infections have contributed to increase the $1-y r$ patient survival after lung transplantation (LTx) to $70-80 \%$ [1]. After successful reduction of early complications, chronic allograft dysfunction has become the major obstacle to long-term survival. A shift in the nature of complications from early to late graft dysfunction has been similarly observed after transplantation of other solid organs [2]. Bronchiolitis obliterans (BO) after LTx was first described in 1984 at Stanford University, Stanford, CA, USA, in heartlung transplant recipients who showed a progressive decline in forced expiratory volume in one second (FEV1) [3]. Lung biopsies from these patients showed intraluminal polyps comprised of fibromyxoid granulation tissue and plaques of dense submucosal eosinophilic scar. Obliteration of small airways by these lesions produces progressive airflow obstruction, often accompanied by recurrent lower respiratory tract infection.

BO and its clinical correlate bronchiolitis obliterans syndrome (BOS) affect up to $50-60 \%$ of patients who survive 5 yrs after surgery, irrespective of the type of transplant procedure $[1,4-6]$. This incidence is high compared with that of chronic graft dysfunction in recipients of liver, heart or kidney transplants (table 1). The time between transplantation and onset of BOS can range from a few months to several years, but in most series, the median time to diagnosis is 16-20 months. In most patients, BOS is a progressive process that responds poorly to augmented immunosuppression, and it accounts for $>30 \%$ of all deaths occurring after the third postoperative year [1]. Survival at 5 yrs after the onset of BOS is only $30-40 \%$, and survival at 5 yrs after transplantation is $20-40 \%$ lower in patients with than in patients without BOS [7]; this difference widens as postoperative follow-up increases. After single LTx, survival after BOS onset is longer in recipients with emphysema compared with recipients with idiopathic pulmonary fibrosis [8].

\section{Clinical presentation}

Clinical symptoms at onset are unspecific or even absent, and many patients only present with an asymptomatic fall in FEV1. However, some patients have an acute presentation with an initial episode of acute rejection or infection that does not respond to treatment. Later in the disease course, symptoms often include repeated episodes of bacterial infection, followed by permanent airway colonisation with pathogenic bacteria and fungi (e.g. Pseudomonas and Staphylococcus spp., and Aspergillus fumigatus). During the first postoperative months, nonspecific bronchial hyperreactivity may be present in patients who will develop BOS later [9]. It is important to emphasise that from the clinical point of view, BOS is a very heterogeneous condition. This probably reflects the variety of risk factors and underlying mechanisms that may be involved (see below). The rate of progression of the disease, as assessed by the decline in FEV1, may show the following: 1) a sudden onset with rapid decline of lung 
Table 1.-Chronic allograft dysfunction in solid organ transplantation

\begin{tabular}{lcc}
\hline Organ & Pathological features & $\begin{array}{c}\text { Incidence 5 yrs } \\
\text { after transplant \% }\end{array}$ \\
\hline Liver & Vanishing bile duct syndrome & 5 \\
Kidney & Glomerular sclerosis/tubular atrophy & 30 \\
Heart & Coronary artery sclerosis & 20 \\
Lung & Bronchiolitis obliterans & $50-60$ \\
\hline
\end{tabular}

function; 2) an insidious onset with a slow, progressive decline over time; and 3) an initial rapid decline in FEV1 followed by a prolonged period of stability [10]. The latter pattern, however, is not very common as $<20 \%$ of affected patients are free of functional degradation at 2 yrs after diagnosis [11].

The risk for progression increases with the number of episodes of acute rejection within 6 months of surgery, and seems to be more pronounced in patients who develop BOS before the second postoperative year [12]. In a recent study of 151 patients with BOS [13], 75\% had a sudden onset of BOS (pattern 1) and $25 \%$ had a chronic onset (pattern 2). Acute onset of BOS occurred earlier relative to surgery than chronic onset, and carried a worse prognosis (median survival after diagnosis 29 versus 58 months). Acute onset of BOS was significantly associated with acute rejection during the first 6 months (though no such event was recorded for many patients), and was often triggered by an acute rejection or infection episode. There is evidence that the number of respiratory infections and the aggressiveness with which they are treated also impact on BOS progression [11]. For example, in the authors' experience, patients who show a very slow decline in FEV1 (pattern 2) generally have few or no respiratory infection and/or airway colonisation.

The presence of BOS negatively affects not only survival but also health-related quality of life [14]. Patients with BOS show less energy and physical mobility, and more depressive symptoms compared with their counterparts without this complication. BOS is also associated with substantial additional healthcare costs, in particular for hospitalisations and medications [15].

\section{Risk factors}

Many factors have been reported as risk factors for BOS [16]. However, quality of data is often a problem, because almost all existing information derives from retrospective studies with no control groups and/or reflects the experience of single centres. Numbers are small and often difficult to interpret. In some cases, risk factors appear to have been more important in the earlier years of LTx, e.g. cytomegalovirus (CMV) infection (see below). Risk factors reported in the literature are designated as probable and potential risk factors in table 2 .

\section{Alloimmune-dependent factors}

The bulk of evidence suggests that BO is mediated by an immunological injury directed toward epithelial and endothelial cells. This is supported by several studies that have shown that acute rejection histology, characterised by perivascular and/or peribronchial infiltration of activated lymphocytes into graft tissue, is a statistical risk factor for BOS; the risk increases when the acute rejection is histologically severe or when it persists or recurs after treatment [11, 16-21]. Three or more episodes of acute rejection within the
Table 2.-Risk factors for bronchiolitis obliterans syndrome (BOS)

\begin{tabular}{|c|c|}
\hline $\begin{array}{l}\text { Probable risk } \\
\text { factors for BOS }\end{array}$ & Potential risk factors for BOS \\
\hline Acute rejection & CMV infection (without pneumonitis) \\
\hline $\begin{array}{l}\text { Lymphocytic } \\
\text { bronchitis/bronchiolitis }\end{array}$ & $\begin{array}{l}\text { Community respiratory virus infection } \\
\text { Donor antigen-specific reactivity }\end{array}$ \\
\hline CMV pneumonitis & Medical noncompliance \\
\hline $\begin{array}{l}\text { Anti-HLA } \\
\text { pretransplantation }\end{array}$ & $\begin{array}{l}\text { Gastro-oesophageal reglux } \\
\text { Older donor age combined with longer } \\
\text { graft ischaemic time }\end{array}$ \\
\hline
\end{tabular}

CMV: cytomegalovirus; HLA: human leukocyte antigen.

first 6-12 months after surgery increase the risk of developing BOS by 3-4 times [11]. Similarly, lymphocytic bronchitis and bronchiolitis in the absence of acute perivascular rejection and infection have been shown to predate BOS in a significant number of patients [19, 21, 22]. Acute rejection later in the postoperative period is another important risk factor [12, 23]; in one study [23], $\sim 50 \%$ of patients treated for acute rejection beyond 6 months after transplantation went on to develop BOS within 3 months of treatment for rejection. In these patients, the absence of a long intervening time period suggests that acute rejection may lead directly to airway obliteration.

However, many patients with acute rejection do not develop BOS, and some patients with BOS have never experienced acute rejection [13]. Therefore, the relationship between acute rejection and BOS appears to be complex and may depend on several factors, such as the time after transplantation, whether acute rejection histology occurs in a symptomatic or asymptomatic patient and on the intensity of therapy provided. In a recent study, A3 or multiple A2 rejection episodes occurred in only $13 \%$ and $7 \%$ of the 96 patients studied, respectively, and their occurrence did not predict BOS. SWANSON et al. [24] suggested that the use of intense induction and maintenance immunosuppression and of aggressive treatment of acute rejection may uncouple the association between early acute rejection and BOS.

Several lines of evidence support the concept that alloreactivity directed towards human leukocyte antigens (HLA) is involved in the pathogenesis of BOS. Patients with antiHLA antibodies pretransplantation have an increased incidence of acute rejection and BOS [25]. The bronchoalveolar lavage (BAL) fluid of stable lung transplant recipients shows a persistent increased percentage of CD8+ T-cells, which suggests subclinical ongoing allogeneic stimulation [26]. Expression of class-I and class-II HLA antigens by bronchial epithelial cells is upregulated during chronic rejection [27-30]. Identification of anti-HLA antibodies directed towards these antigens in previously unsensitised recipients is associated with, or may even precede, the development of BOS [31, 32]. In addition, reactivity of bronchoalveolar [33] and peripheral blood [34] lymphocytes in patients with BOS is generally directed towards donor-specific class-I HLA antigens. Despite these observations and single-centre reports of an association between HLA mismatching and BOS [35], analysis of the United Network for Organ Sharing/International Society for Heart and Lung Transplantation (ISHLT) database [36] and a recent review of the published literature [16] do not support HLA mismatching as an established risk factor for chronic rejection. This is probably related to the fact that very few patients have two or less HLA mismatches because no attempt at HLA matching is made.

Persistent donor antigen-specific reactivity of recipient $\mathrm{T}$-lymphocytes has reportedly led to increased rates of BOS, 
and conversely donor-specific hyporeactivity (generally associated with peripheral blood allogeneic microchimerism) has been reported to be protective in some $[37,38]$, but not in all [39], studies. Preliminary experience from the Pittsburgh (PA, USA) transplant group has shown that the infusion of donor bone marrow in combination with LTx increases donor cell chimerism and donor-specific hyporeactivity, and is associated with a lower incidence of BOS [40]. In this study, two of 22 patients $(9 \%)$ who received bone marrow infusion developed $\mathrm{BO}$ and/or BOS versus five of 12 control patients $(42 \%)$; the significance of these results, however, is limited by the small number of patients studied and the short duration of the follow-up.

\section{Alloimmune-independent factors}

Although BOS is thought to be mediated by an alloimmunological injury, it is likely that nonalloimmunological inflammatory conditions also play a role. The lung is constantly exposed to inhaled agents, such as antigens, toxins and irritants, which promote local inflammation. In addition, the allograft is particularly susceptible to inhaled exogenous infectious agents [41-43]. Bacterial and fungal infections are not known to contribute directly to the pathogenesis of BOS, though they may increase the risk of acute rejection [21]. In contrast, CMV-related illness has been implicated in chronic vascular rejection of nonpulmonary solid organ transplants, and in some studies CMV pneumonitis was correlated with the development of BOS [12]. In the ISHLT registry [1], CMV mismatch is reported as a risk factor for 1- and 5-yr mortality. However, the impact of CMV on the development of BOS remains controversial, possibly due to several factors, such as the matching of CMV-seronegative recipients with CMVseronegative donors, the prospective monitoring of $\mathrm{CMV}$ antigenaemia as a surveillance technique for CMV infection, the use of prophylactic or pre-emptive antiviral treatments and changes in the immunosuppressive regimen, all of which may mask potential associations [44]. Several centres have reported a decreased risk of CMV in the development of BOS, either a decreased incidence or a delayed onset, after the use of CMV prophylaxis [45-47].

Community respiratory virus infections, including respiratory syncytial virus, parainfluenza virus, adenovirus, and influenza A and B occur frequently in lung transplant recipients [48, 49]. Although these viruses have not been unequivocally associated causally with BOS, their involvement cannot be excluded. In the study by BILLINGS et al. [48], patients with community virus infections involving the lower respiratory tract were predisposed to high-grade BOS development.

The role of airway ischaemia in the pathogenesis of BOS is uncertain. Ischaemia may occur as a result of two mechanisms. First, chronic ischaemia due to interruption of the bronchial artery supply after reimplantation of the graft is a potential facilitator of subsequent small airway injury, however, the fact that bronchial artery revascularisation at the time of surgery has not significantly reduced the prevalence of BOS argues against the role of chronic airway ischaemia [50]. Secondly, "cold ischaemia" that occurs during the time interval between organ procurement and organ transplantation has been suggested to increase the risk of death and chronic graft dysfunction after LTx. In the study by Novick et al. [51], the effect of ischaemia time on the incidence of BOS was magnified as donor age increased, suggesting that the susceptibility to ischaemic injury at the time of organ procurement is dependent on additional intrinsic donor characteristics.
Recently, gastro-oesophageal reflux disease (GERD) has been reported to be associated with BOS. GERD is common after LTx, in part due to intraoperative injury to the vagal nerve and medication-induced gastroparesis. Afferent denervation of the airways also diminishes the chronic cough associated with GERD. Transplant recipients may thus be insensitive to microaspiration that may promote chronic inflammation and bacterial infections in the lower airways, and hence may be a risk factor for BOS [52]. Antireflux surgery (fundoplication) in transplant patients may improve lung function [52-54].

Medication noncompliance may represent an important, but often underestimated, risk factor for chronic rejection $[55,56]$. For example, 12 months after kidney transplantation, the rate of compliance with a multidrug immune suppressive regimen was only 48\% [56]. Although similar studies are not available in lung transplant recipients, medication noncompliance should be considered as a potential risk factor for BOS.

Several additional factors have been proposed as risk factors for BOS, but convincing data to support their role is lacking [16]. These factors include a history of smoking or asthma in the donor, donor age, head injury as cause of death, reperfusion injury, primary pulmonary hypertension as recipient primary disease, organising pneumonia, and genotypic suceptibility related to cytokine gene polymorphisms $[57,58]$.

\section{Pathogenesis}

The histopathological features of BO suggest that injury and inflammation of epithelial cells and subepithelial structures of small airways lead to excessive fibroproliferation due to ineffective epithelial regeneration and aberrant tissue repair [59]. In parallel with the concept of "injury response" that has been proposed to explain chronic dysfunction of other organ allografts [60], the evolving concept is that $\mathrm{BO}$ represents a "final common pathway" lesion, in which various insults (see above) can lead to a similar histological result. Accordingly, the cellular mechanisms discussed here may all contribute to the development of $\mathrm{BO}$, irrespective of the nature of the initial injury and offending agent.

\section{Animal models}

Experimental studies have used the orthotopic LTx model and the heterotopic airway transplantation model. The first model consists of an orthotopic left single LTx performed in small animals like rats [61] and large animals like pigs [62]. It is mostly used to study acute events, since chronic changes such as BO occur infrequently in this model [62-64]. In contrast, the heterotopic airway transplantation model leads to consistent and reproducible airway obliteration and produces a histological lesion, which is very similar to that of human BO. The model, which was developed in the early 1990 s in mice [65] and rats [66, 67], is technically less demanding than the orthotopic model and can be produced in larger numbers [68]. Although the heterotopic airway transplantation model has proved very useful to improve the understanding of the pathogenesis of $\mathrm{BO}$, it differs from the clinical situation in several aspects. First, the transplanted airways are not primarily revascularised but depend on neovascularisation, and therefore, are exposed to pronounced ischaemia. In this model, however, airway ischaemia alone does not lead to airway obliteration [69]. Secondly, clinical $\mathrm{BO}$ is a chronic process that usually starts a few months after 
surgery. In contrast, airway obliteration occurs within a few weeks after transplantation in the airway transplantation model, in particular when no immunosuppression is given and when allografts from fully major histocompatibility complexmismatched animal strains are used.

Histologically, the heterotopically transplanted trachea shows an initial ischaemic phase [69], followed by marked lymphocytic infiltration with complete epithelial loss, and then by fibrous obliteration of the airway lumen. In the tracheal allograft model, injury to the epithelium is immunemediated, but interestingly, nonimmune-mediated injury to the epithelium of tracheal isografts (e.g. produced by protease digestion) may also lead to airway obliteration [70]. In both the allograft and the isograft models, the loss of epithelium plays a pivotal role in this process. Thus, epithelial cell replacement in denuded isografts can significantly reduce airway obliteration [71]. After the epithelium is lost, thickening and fragmentation of the basement membrane can be observed [72].

The loss of basement membrane integrity will allow lymphocytes to infiltrate the tracheal mucosa, producing a histological picture that closely resembles the lymphocytic bronchitis and bronchiolitis seen in humans. Lymphocytic inflammation of the airway thus seems to be a precursor of BO [69]. Infiltrating cells include CD4+ and CD8+ T-cells (with a higher proportion of CD8+ cells early on $[67,73]$ ), natural killer cells and macrophages [74], and later, myofibroblasts [73]. Recipient T-cells will recognise donor major histocompatability complex class-I and class-II alloantigens by both direct and indirect pathways $[75,76]$. T-cell activation requires co-stimulatory signals. It has been shown that cellular infiltration and airway obliteration highly depend on host CD40 ligand and to a lesser degree on CD28 [72]; the interaction of CD28 with its ligand B7-2, but not B7-1, is involved in upregulating proinflammatory and T-helper (Th) cell type-1 cytokine responses [77]. Consistent with this, treatment with cytotoxic T-lymphocyte antigen 4-immunoglobulin G (CTLA4-IgG), which blocks the CD28/B7 co-stimulatory pathway, delays epithelial injury and attenuates obliterative changes. When administration of CTLA4-IgG and FTY720 (which induces T-cell apoptosis and sequestration of circulating mature lymphocytes) are combined, the integrity of both epithelium and airway lumen is maintained [78].

Mediators involved in the process include a strong and persistent Th1-type response with upregulation of interferon$\gamma$ and interleukin (IL)-2 accompanied by a mild upregulation of Th2 cytokines, such as IL-4 and IL-10 [79]. The Th1 response persists even after completion of the airway obliteration, indicating ongoing immune stimulation [80]. $\mathrm{CC}$ as well as $\mathrm{CXC}$ chemokines and their receptors play an important role in the recruitment of intragraft leukocytes. RANTES (regulated upon activation, normal T-cell expressed and secreted), a chemoattractant for memory T-cells, monocytes and eosinophils, has been shown to be highly expressed in mononuclear cells infiltrating the tracheal allograft [80]; the use of a neutralising anti-RANTES antibody decreases the number of CD4+ infiltrating T-cells and prevents airway obliteration [81]. Similarly, monocyte chemoattractant protein (MCP)-1 acting through its receptor CCR2 is a potent chemoattractant for mononuclear cell. Loss of MCP-1/CCR2 signalling significantly reduces mononuclear cell recruitment and later airway obliteration [82].

Typical cells involved in the fibroproliferative phase are fibroblast-like cells that express type-III collagen messenger ribonucleic acid (mRNA) [83]. Mediators include profibrotic cytokines, such as platelet-derived growth factor (PDGF), fibroblast growth factor, transforming growth factor (TGF)- $\beta$, insulin-like growth factor (IGF)-1 and endothelin (ET)-1 [84]. These cells and mediators promote extracellular matrix deposition, proliferation of smooth muscle cells, angiogenesis and excessive fibroproliferation.

In addition to its contribution to the identification of several cellular mechanisms involved in BO, the animal models have been used to understand how CMV infection may enhance BO [85], to test protocols of orally induced tolerance [63] and to assess the effectiveness of novel immunosuppressive agents (and other compounds) in the prevention of airway obliteration [86-92].

\section{Human studies}

As in the animal model, there is evidence that damage to the airway epithelium plays a key role in the cascade of events leading to human BOS. As noted above, indirect allorecognition of donor HLA class-I peptides in patients with BOS may lead to sensitisation of T-cells [34] and production of antiHLA class-I antibodies [31]. These antibodies, in turn, may induce proliferation of airway epithelial cells in vitro [93]. Furthermore, non-HLA antibodies directed against airway epithelial cells are found in some patients with BOS, and binding of such antibodies to epithelial cells may upregulate growth factors like TGF- $\beta$ [94].

In patients with BOS, bronchial epithelial cells overexpress the Ki-67 antigen [30] (which is a proliferation marker) and co-stimulatory B7 molecules [95]. As a result of epithelium destruction, there is a decline in Clara cell function and protein production with decreased concentration in BAL fluid [96]. This reduction may render the bronchiolar epithelium more sensitive to oxidative stress (see below), and promote both inflammation and fibroproliferation. The bronchial epithelium is also an important source of chemokines that attract neutrophils (see below).

Endobronchial biopsies show that the bronchial epithelium of patients with BOS contains increased numbers of dendritic cells (DC) [97, 98], with a higher proportion of antigenpresenting cells and a lower proportion of "suppressor" macrophages. In addition, these DC express co-stimulatory molecules of the B7 family (in particular the B7-2), which are capable of inducing optimal T-cell stimulation [97]. Thus, epithelial DC in lung transplant recipients presumably activate local and systemic immune responses, which may contribute to the process of chronic rejection.

With BOS development, BAL neutrophilia (and eosinophilia) increase [99-102] above levels seen in stable patients $[26,101,103,104]$. However, whether this is a specific feature of BOS or whether it reflects concomitant airway infection is still debated. The increased neutrophilia is also found in induced sputum [105] and in lung tissue [30]. Besides the physiological function of clearing invading microorganisms, activated neutrophils have a large potential to cause damage to lung tissue through the generation of reactive oxygen species (ROS) and the release of proteases [106]. Markers of granulocyte activation, such as the oxydative enzymes myeloperoxidase and eosinophil cationic protein, may be detected in BAL fluid months before the clinical onset of BOS [107-111]. Lung transplant recipients without BOS already have a compromised antioxidant status [112], but the oxidative stress substantially increases when BOS develops $[109,110]$. The increased oxidative stress may simply reflect neutrophil influx in the airways, but iron overload caused by microvascular leakage may be an additional mechanism [113, 114]. BOS is also associated with impaired antiprotease activity, evident from decreased concentrations of BAL secretory leukocyte protease inhibitor [109]. Furthermore, unopposed neutrophil elastase activity is frequently found in lung transplant recipients, usually in association with 
endobronchial bacterial infection in the context of BOS [111]. At present, it is not entirely clear whether the increased oxidative stress and impaired protease/antiprotease balance should be merely considered as markers of BOS or whether they may be directly involved as pathogenic mechanisms.

The important role played by neutrophils in the pathogenesis of human BOS differs from what is seen in animal models where graft infiltration is mainly of lymphocytic origin (see above). This difference may be explained by several factors. First, in the rat, circulating blood lymphocyte concentrations are higher (40-80\% of total leukocyte count) than in humans. Secondly, the animals are kept under strict sterile conditions and the subcutaneously placed allograft has no contact to the environment; as a result, the primary injury leading to airway obliteration is alloimmune in nature, and hence driven by lymphocytes. In contrast, bronchial infection or aspiration, which typically elicit neutrophilic infiltration, may be present in the clinical setting. Thus, unlike what is seen in human BOS (see below), macrophage inflammatory protein-2, which is the functional rodent correlate of human IL-8 and has potent neutrophil-chemoattractant properties, is upregulated only in the first few days after transplantation [80].

One of the major mediators of airway inflammation in human BOS is IL-8, a member of the CXC chemokine family and a key chemoattractant and activating factor for neutrophils. IL-8 is produced by bronchial epithelial [115] and smooth muscle cells [116], and its concentration in BAL fluid of BOS patients highly correlates with airway neutrophilia [99, 102, 107, 115, 116]. Attraction of neutrophils and eosinophils may also be induced by ET-1, which is upregulated during bacterial infections in lung transplant recipients [117]. ET-1 has profibrotic properties and is involved in the airway remodelling of several inflammatory diseases. As in the heterotopic airway model in animals, increased BAL concentrations of MCP-1 [99], RANTES [102] and growth factors (PDGF [118], IGF-1 [119], and TGF- $\beta$ [115, 120-122]) are found in human BOS. These profibrotic cytokines are responsible for an increased fibroblast-proliferative activity in BAL supernatant [123]. In addition to the effects of growth factors, the "fibrolytic" activity of IL-1 is inhibited by increased levels of IL-1-receptor antagonist, resulting in a local profibrotic environment [123].

\section{Summary}

Taken together, accumulated experience from human and animal studies suggests that alloimmune and/or nonalloimmune injury to the airway epithelium triggers a massive influx of inflammatory cells through the fragmented basement membrane, and the secretion of proinflammatory cytokines (IL-2, IL-6, tumour necrosis factor (TNF)- $\alpha$ ) and chemokines (IL-8, RANTES, MCP-1) by epithelial cells, T-cells, activated macrophages and smooth muscle cells (fig. 1). In human BOS, this leads to attraction and accumulation of activated neutrophils; these cells promote production of additional cytokines and chemokines that amplify cell recruitment, and release large amounts of ROS and toxic proteases that produce further airway injury. Macrophages typically produce profibrotic cytokines that elicit attraction and proliferation of fibroblasts, leading to extracellular matrix deposition and proliferation of smooth muscle cells. Thus, after an initial epithelial injury, ineffective epithelial regeneration and massive inflammation eventually produce aberrant tissue repair with scar tissue obliterating the airway lumen.

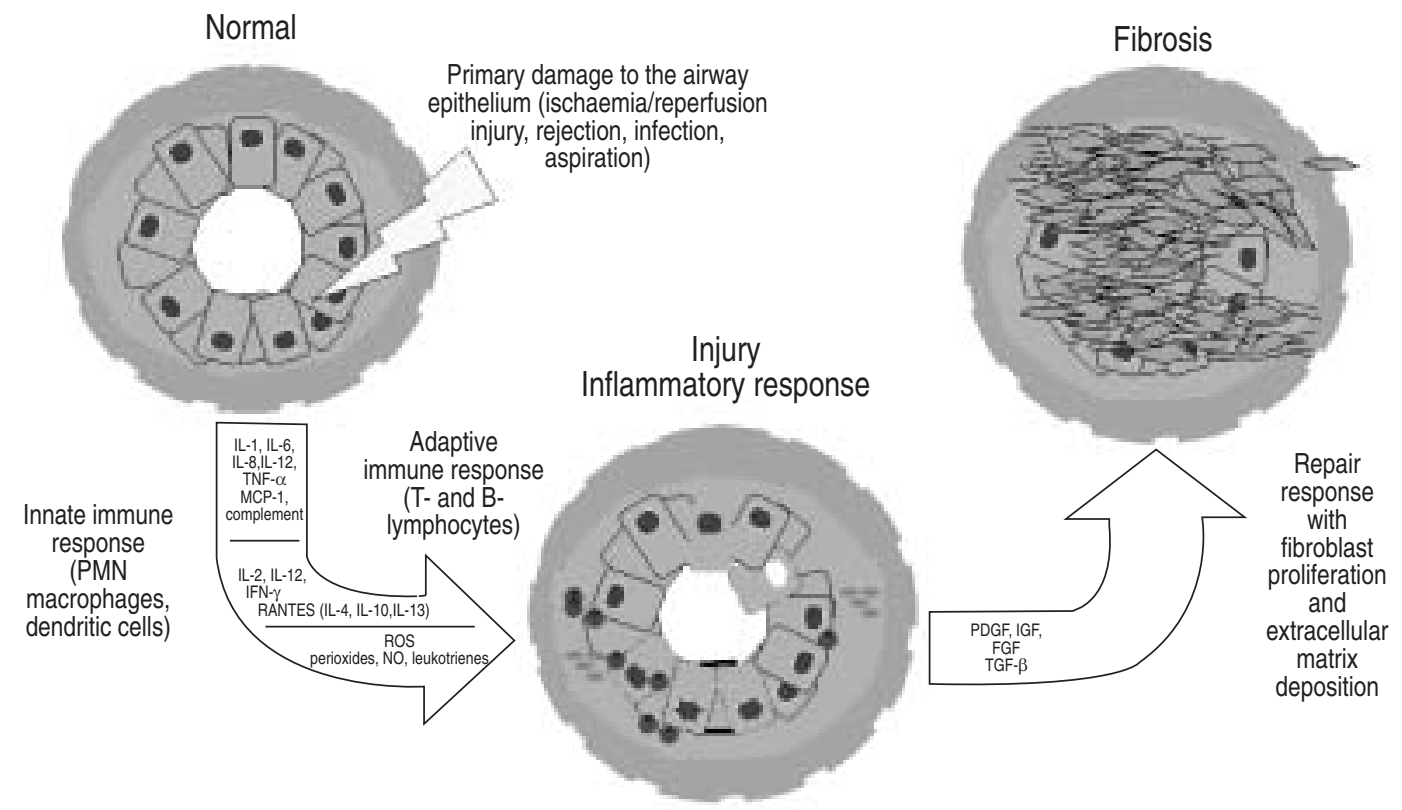

Fig. 1.- Primary damage to the lung allograft leads to activation of the innate immune system, which by interaction of dendritic cells and Tlymphocytes is followed by activation of the adaptive immune system. Injury to the airway epithelium and loss of epithelium leads to repair mechanisms finally ending in intrabronchiolar scar formation. PMN: polymorphonuclear; IL: interleukin; TNF: tumour necrosis factor; MCP: monocyte chemoattractant protein; IFN: interferon; RANTES: regulated on activation, T-cell expressed and secreted; ROS: reactive oxygen species; NO: nitric oxide; PDGF: platelet-derived growth factor; IGF: insulin-like growth factor; FGF: fibroblast growth factor; TGF: transforming growth factor. 


\section{Staging}

The diagnosis of BO is based on histology, but a histological proof is often difficult to obtain using transbronchial lung biopsies. Therefore, in 1993, a committee sponsored by the ISHLT proposed a clinical description of BOS based on changes in FEV1 [124]. The aims were to provide a classification system for airway disease after LTx that did not rely on histopathological findings, was sensitive and specific, relied on diagnostic techniques available to all lung transplant physicians, and was relatively simple to understand and apply. For each patient, a stable post-transplant baseline FEV1 was defined as BOS stage 0; in patients who experienced a decrease in FEV1, progressive stages of BOS, from 1-3, were defined according to the magnitude of the decrease (table 3). The functional alteration has to be irreversible (i.e. be present for a period of $\geqslant 3$ weeks) and not be explained by other conditions that may alter graft function; when such conditions are found, the diagnosis of BOS can only be made if the functional alteration persists after appropriate treatment [17].

Although this classification system has been adopted by transplant centres worldwide as a useful descriptor of chronic allograft dysfunction, concern has been raised regarding its ability to detect small changes in pulmonary function. This concern recently led to formulation of a revised classification system for BOS [17], which includes a new "potential BOS" stage (BOS 0-p) defined as a decrease in forced mid-expiratory flow rates (FEF25-75\%) and/or FEV1 (table 3). The rationale for including FEF25-75\% comes from studies that showed that this variable deteriorates before FEV1 at the onset of BOS $[100,125,126]$. The new BOS 0 -p stage is meant to alert the physician and to indicate the need for close functional monitoring and for in-depth assessment using surrogate markers for BOS (see below).

Most data supporting the usefulness of monitoring the FEF25-75\% have been obtained in recipients of heart-lung and bilateral-lung, rather than single-lung grafts. In the latter, the presence of the native lung may make interpretation of functional changes more difficult. Disease progression in the native lung and complications affecting this lung may contribute to a change in overall lung function. In patients with emphysema, progressive hyperinflation of the native lung may produce clinical and functional changes that resemble those produced by BOS [127]. These confounding factors may explain, at least in part, that in a recent retrospective study performed in single-lung transplant recipients, FEF25-75\%

Table 3. - Bronchiolitis obliterans syndrome (BOS) classification system

1993 Classification 2002 Classification

\begin{tabular}{|c|c|c|c|}
\hline & $\begin{array}{l}\text { FEV } 1 \geqslant 80 \% \text { of } \\
\text { baseline }\end{array}$ & $\begin{array}{l}\text { FEV } 1>90 \% \text { of baseline } \\
\text { and FEF } 25-75 \%>75 \% \\
\text { of baseline }\end{array}$ & BOS 0 \\
\hline & & $\begin{array}{l}\text { FEV1 } 81-90 \% \text { of baseline } \\
\text { and/or FEF } 25-75 \% \leqslant 75 \% \\
\text { of baseline }\end{array}$ & BOS $0-p$ \\
\hline BOS 1 & $\begin{array}{l}\text { FEV1 } 66-80 \% \text { of } \\
\text { baseline }\end{array}$ & FEV1 $66-80 \%$ of baseline & BOS 1 \\
\hline BOS 2 & $\begin{array}{l}\text { FEV1 } 51-65 \% \text { of } \\
\text { baseline }\end{array}$ & FEV1 $51-65 \%$ of baseline & BOS 2 \\
\hline BOS 3 & $\begin{array}{l}\text { FEV1 } \leqslant 50 \% \text { of } \\
\text { baseline }\end{array}$ & FEV $1 \leqslant 50 \%$ of baseline & BOS 3 \\
\hline
\end{tabular}

FEV1: forced expiratory volume in one second; FEF25-75\%: forced mid-expiratory flow rates. was shown to be a very sensitive, but not specific, indicator of the subsequent development of BOS [128].

The classification system for BOS has proved useful to categorise patients according to the degree of chronic graft dysfunction, and has allowed transplant centres to use a common language to compare results and therapy from their programmes. However, the implication for an individual patient to be categorised in a given stage is less clear because different patients may have vastly different patterns of BOS acquisition and subsequent progression (see above). This is the reason why the classification system is not intended to be used to construct treatment algorithms and make therapeutic decisions. Such algorithms would need to include informations on the patient risk factors, history of rejection and infection, previous and current immunosuppression, and pattern of BOS onset and progression [129].

\section{Prevention and early detection}

To the extent that current therapies work to stop or slow down the progression of BOS, they do so mostly by an antiinflammatory, and not an antifibrotic effect. Therefore, they are more likely to be effective in the early stage of BOS. For this reason, various parameters have been evaluated to determine whether they may be useful as early markers of a fall in graft performance.

\section{Surveillance transbronchial biopsy}

Several studies have shown that surveillance transbronchial biopsy (TBB) performed during the first postoperative months may show acute rejection histology in $22-73 \%$ of clinically and physiologically stable patients [24, 130, 131]. Similarly, a recent study that used home monitoring of FEV1 and FEF $25-75 \%$ via the internet to detect acute rejection (and infection) found a sensitivity of only $63 \%$ because many episodes detected by surveillance TBB were not associated with significant functional changes [132]. Thus, the performance of surveillance TBB in the first months after surgery provides a means to detect and treat clinically silent rejection episodes, and may dictate the use of a more intense maintenance immunosuppression. This strategy may eventually prove useful to uncouple the association between acute rejection and BOS [24]. In addition, BANDO et al. [18] have reported that $\mathrm{BO}$ resolved or stabilised in $87 \%$ of patients in whom the diagnosis was made by surveillance TBB (i.e. who were asymptomatic and in BOS stage 0 at the time of diagnosis). However, no information on the long-term functional evolution of these patients was provided, and the apparent resolution of $\mathrm{BO}$ histology may simply reflect a sampling error on subsequent biopsies. Whether or not early initiation of augmented immunosuppression may slow down progression of the disease, both consistently and in the long term, thus remains to be established.

\section{Pulmonary function}

A potential limitation of the staging system proposed by the ISHLT is that hospital spirometry may be performed infrequently, especially in patients who live at great distances from transplant centres. This limitation, however, may be overcome by the use of home spirometry with telemetric transmission of functional data to the transplant centre [133]. Alterations in the distribution of ventilation in peripheral airways may also contribute to the early detection of BOS. 
Two recent prospective studies in heart-lung and bilaterallung recipients have shown that the slope of the alveolar plateau for nitrogen or helium obtained during single-breath washouts (that reflects the heterogeneity of ventilation distribution) may increase up to several months before the criteria for BOS $0-p$ are met $[100,125]$. Finally, the presence of nonspecific bronchial hyperreactivity may also precede BOS. In a recent longitudinal study that included 111 patients undergoing bilateral LTx, a positive methacholine challenge at 3 months after transplantation was associated with the development of BOS, with a positive predictive value of $72 \%$ [9]. This observation may be related to the fact that, in transplanted subjects, methacholine-induced bronchoconstriction involves the small airways [134].

\section{Bronchoalveolar lavage}

At least three reports have shown that BAL neutrophilia may predate the spirometric criteria defining BOS $1[100,102$, 116], and cross-sectional studies of patients with BOS have demonstrated increased concentrations of various cytokines in the BAL (see above) [99, 102, 107, 115, 116, 118, 119]. These alterations, as well as the increase in BAL fibroblastproliferative activity [123], may precede the functional alteration of BOS, suggesting that overexpression of cytokines may be predictive of BOS onset. However, the overlap of concentrations found in patients with and without BOS, the fact that measurements of these markers are not currently available at most transplant centres, and the cost of such measurements are all expected to limit their clinical application.

\section{Induced sputum}

Sputum induction, a noninvasive method to measure inflammation of the lower respiratory tract, was recently evaluated in patients with BOS [105]. Similarly to BAL findings, increased neutrophil counts have been found. In addition, matrix metalloproteinase (MMP)-9 and the ratio of MMP-9 to its inhibitor have been found to be elevated in BOS patients; MMP-9 correlated negatively with FEV1 values and positively with sputum neutrophils and TNF- $\alpha$ [135]. The usefulness of induced sputum analysis for the early detection of BOS remains to be investigated in larger studies.

\section{Exhaled breath condensate}

Volatile and nonvolatile markers originating from the respiratory tract can be measured in breath condensate [136]. To date, eicosanoids, products of lipid peroxidation, vasoactive amines, nitric oxide (NO)-related products, ammonia, hydrogen ions and cytokines have been measured, and there is hope that this method may contribute to the early detection of BOS in the future. Only exhaled carbonyl sulphide as a marker of acute rejection [137] and leukotriene $\mathrm{B}_{4}$ as a marker of infection [138] have been described in the lung transplant population.

\section{Exhaled nitric oxide}

Exhaled nitric oxide (eNO) concentration, which has been proposed as a noninvasive marker of airway inflammation, may be useful in the early detection of BOS. It is elevated in patients with lymphocytic bronchiolitis and in patients with
BOS, in particular at the onset of the functional deterioration (BOS 1). Concentrations of eNO correlate with the expression of inducible NO synthase in the bronchial epithelium and with the percentage of neutrophils in BAL [139-141]. These data indicate that eNO reflects the degree of airway inflammation in lung transplant recipients [142], but the extent to which eNO may predict the development of BOS in an individual patient remains to be established.

\section{Computed tomography}

The presence of air trapping on expiratory high-resolution computed tomography (CT) is an accurate indicator of the bronchiolar obliteration underlying BOS. In patients with BOS, the pulmonary lobules that have normal airways increase in density during the expiratory phase, while areas with obstructed airways cannot empty and remain radiolucent. Studies in adults and children have shown that the sensitivity of air trapping for enabling the diagnosis of BOS and $\mathrm{BO}$ ranges $74-91 \%$ while the specificity ranges $67-94 \%$ $[143,144]$. This variability may be accounted for by differences in the technique used to quantify the extent of air trapping, and by the fact that some studies included both heart-lung or bilateral-lung and single-lung transplant recipients [144]. Interestingly, in the study by BANKIER et al. [143], five of the six patients with initial false-positive findings (with significant air trapping but an FEV1 $>80 \%$ of baseline) later developed BOS, which suggests that expiratory CT may contribute to the early detection of the condition. Conversely, air trapping has a very high negative predictive value $(>90 \%)$, i.e. a low score of air trapping in a patient with declining lung function makes the diagnosis of BOS very unlikely. The extent to which these results may apply to recipients of singlelung grafts is unknown.

\section{Clinical management}

The various approaches to the treatment of BOS have been described in detail in an earlier chapter. Several issues may deserve attention in the decision-making process of selecting a specific treatment for BOS. As discussed previously, it is likely that BOS represents a heterogeneous syndrome, with alloimmune and nonalloimmune mechanisms predominating to variable degrees in individual patients. To the greatest extent possible, lung transplant physicians should attempt to discern these differences and individualise therapy. For example, it may be more appropriate to have an aggressive therapeutic attitude in patients with rapid, as opposed to slow, BOS onset. Many patients with BOS suffer from recurrent bacterial, viral and fungal infections that further compromise lung function and often become the proximate cause of death [41-43]. Therefore, vigorous efforts to identify and treat infections are warranted during exacerbations of respiratory illness in recipients with BOS. It is also likely, although unproven, that aggressive immunosuppressive treatment of BOS predisposes to intercurrent bronchopulmonary infections; in patients with repeated infections, some physicians regard decreasing immunosuppression as an option. It is clear that the infectious risk must be factored into the riskbenefit analysis of augmented immunosuppression.

Current therapies, when effective, will necessarily preserve the most lung function if they are employed early in the evolution of the disease process. In this regard, it is possible that lung recipients with risk factors for chronic rejection, such as prior episodes of acute rejection, CMV pneumonitis, lymphocytic bronchiolitis, or anti-HLA antibodies, may benefit from intensified immunosuppressive therapy, even 
prior to observing a decrease in pulmonary function (or while in BOS 0-p) [24]. However, this approach is rarely taken by lung transplant physicians due to the relatively low predictive value of currently recognised risk factors and the known risks of increased immunosuppression. In addition to the infectious risk mentioned above, progressive kidney insufficiency and bone fractures will inevitably alter patient survival and/or quality of life. Therefore, an important goal for future research will be to validate the surrogate markers described above in longitudinal studies, and to develop more sensitive and specific noninvasive biomarkers of the risk for progression to BOS.

\section{Suggestions for future research}

Post-transplant BO has become the major hurdle to longterm survival after LTx. Although considerable information has been gained in the understanding of the pathogenesis of this complication, its prevalence has not substantially decreased over time and it remains the first cause of late death in lung transplant recipients. This is due to the fact that, to date, no treatment has proved efficient to reverse established BOS, or even to slow down the progression of the functional deterioration. The following are some suggestions for future research.

\section{Bronchiolitis obliterans syndrome classification}

The term BOS is currently used to qualify chronic allograft dysfunction (whatever the underlying cause/mechanism). The staging system has proved useful to categorise patients according to the degree of functional impairment and has allowed transplant centres to use a common language to compare results from their programmes. However, from the therapeutic point of view, the use for an individual patient to be diagnosed in any particular BOS category is not established, because patients in a given stage may have vastly different patterns of disease progression. Both the cause of BOS and the rate of functional decline, which are not currently included in the classification, may have important implications when making decisions about treatment [129].

\section{Risk factors}

Most data regarding risk factors for BOS come from retrospective studies. Longitudinal studies evaluating all suspected risk factors should be undertaken in a sufficiently large number of patients to reach the statistical power needed to assess the relative risk associated with each factor. Among others, the following factors should be studied: 1) preoperative characteristics of recipient (primary disease, HLA sensitisation) and donor (cause of death, age, history of asthma and smoking); 2) matching of donor and recipient sex, CMV status, and HLA antigens; 3) presence and severity of ischaemia/reperfusion injury; 4) episodes of CMV infection, acute rejection and community respiratory viral infection; and 5) presence of gastro-oesophageal reflux disease. In these studies, specific attention should be given to clarify the relationship between acute rejection and subsequent BOS development.

\section{Pathogenesis}

A number of abnormalities have been observed in the BAL of patients with BOS, but they do not necessarily directly contribute to the pathogenesis of BOS, i.e. they may merely be disease markers. In addition, the variable pathogenic mechanisms and time course of BOS have not been correlated with differences at the level of cellular and molecular markers. The evolving technologies of functional genomics and proteomics, which allow simultaneous comparisons of large numbers of mRNA or protein species between individuals or over time in a single individual, will likely yield a more comprehensive and informative view of the development of bronchiolar fibrosis.

\section{Early detection}

Longitudinal studies using several potential early markers (lung function, BAL analysis, analysis of exhaled gases and breath condensate, CT etc.) should be performed to assess the time course of changes and their ability to predict future decreases in lung function. The validity of some markers (e.g. FEF25-75\%, air trapping on CT) remains to be established in recipients of single-lung transplants.

\section{Treatment}

Prospective studies are needed to determine if changes (and which changes) in immunosuppressive regimens made at the onset of bronchiolitis obliterans syndrome may alter the subsequent evolution of the process. Developing effective antifibroproliferative therapies (based on either novel immunosuppressive agents or cytokine/chemokine antagonists [81, $84,120]$ ) may well eventually be the best treatment option for bronchiolitis obliterans syndrome.

\section{References}

1. Hertz MI, Taylor DO, Trulock EP, et al. The Registry of the International Society for Heart and Lung Transplantation: nineteenth official report - 2002. J Heart Lung Transplant 2002; 21: 950-970.

2. Pascual M, Theruvath T, Kawai T, Tolkoff-Rubin N, Cosimi B. Strategies to improve long-term outcomes after renal transplantation. N Engl J Med 2002; 346: 580-590.

3. Burke CM, Theodore J, Dawkins KD, et al. Post-transplant obliterative bronchiolitis and other late lung sequelae in human heart-lung transplantation. Chest 1984; 86: 824-829.

4. Boehler A, Kesten S, Weder W, Speich R. Bronchiolitis obliterans after lung transplantation. Chest 1998; 114: 14111426.

5. Boehler A, Estenne M. Obliterative bronchiolitis after lung transplantation. Curr Opin Pulm Med 2000; 6: 133-139.

6. Estenne M, Hertz MI. Bronchiolitis obliterans after human lung transplantation. Am J Respir Crit Care Med 2002; 166: $440-444$.

7. Valentine VG, Robbins RC, Berry GJ, et al. Actuarial survival of heart-lung and bilateral sequential lung transplant recipients with obliterative bronchiolitis. J Heart Lung Transplant 1996; 15: 371-383.

8. Haider Y, Yonan N, Mogulkoc N, Carroll KB, Egan JJ. Bronchiolitis obliterans syndrome in single lung transplant recipients-patients with emphysema versus patients with idiopathic pulmonary fibrosis. $J$ Heart Lung Transplant 2002; 21: 327-333.

9. Stanbrook MB, Kesten S. Bronchial hyperreactivity after lung transplantation predicts early bronchiolitis obliterans. Am J Respir Crit Care Med 1999; 160: 2034-2039.

10. Nathan SD, Ross DJ, Belman MJ, et al. Bronchiolitis obliterans in single-lung transplant recipients. Chest 1995; 107: 967-972.

11. Heng D, Sharples LD, McNeil K, Stewart S, Wreghitt T, 
Wallwork J. Bronchiolitis obliterans syndrome: Incidence, natural history, prognosis, and risk factors. J Heart Lung Transplant 1998; 17: 1255-1263.

12. Kroshus TJ, Kshettry VR, Savik K, John R, Hertz MI, Bolman RM 3rd. Risk factors for the development of bronchiolitis obliterans syndrome after lung transplantation. J Thorac Cardiovasc Surg 1997; 114: 195-202.

13. Jackson CH, Sharples LD, McNeil K, Stewart S, Wallwork J. Acute and chronic onset of bronchiolitis obliterans syndrome (BOS): are they different entities? J Heart Lung Transplant 2002; 21: 658-666.

14. van den Berg JW, Geertsma A, van der Bij W, et al. Bronchiolitis obliterans syndrome after lung transplantation and health-related quality of life. Am J Respir Crit Care Med 2000; 161: 1937-1941.

15. van den Berg JW, van Enckevort PJ, Ten Vergert EM, Postma DS, van der Bij W, Koeter GH. Bronchiolitis obliterans syndrome and additional costs of lung transplantation. Chest 2000; 118: 1648-1652.

16. Sharples LD, McNeil K, Stewart S, Wallwork J. Risk factors for bronchiolitis obliterans: a systematic review of recent publications. J Heart Lung Transplant 2002; 21: 271-281.

17. Estenne M, Maurer JR, Boehler A, et al. Bronchiolitis obliterans syndrome 2001: An update of the diagnostic criteria. J Heart Lung Transplant 2002; 21: 297-310.

18. Bando K, Paradis IL, Similo S, et al. Obliterative bronchiolitis after lung and heart-lung transplantation. An analysis of risk factors and management. $J$ Thorac Cardiovasc Surg 1995; 110: 4-14.

19. Husain AN, Siddiqui MT, Holmes EW, et al. Analysis of risk factors for the development of bronchiolitis obliterans syndrome. Am J Respir Crit Care Med 1999; 159: 829-833.

20. Sharples LD, Tamm M, McNeil K, Higenbottam TW, Stewart S, Wallwork J. Development of bronchiolitis obliterans syndrome in recipients of heart-lung transplantation - early risk factors. Transplantation 1996; 61: 560-566.

21. Girgis RE, Tu I, Berry GJ, et al. Risk factors for the development of obliterative bronchiolitis after lung transplantation. J Heart Lung Transplant 1996; 15: 1200-1208.

22. Ross DJ, Marchevsky A, Kramer M, Kass RM. Refractoriness of airflow obstruction associated with isolated lymphocytic bronchiolitis/bronchitis in pulmonary allografts. $J$ Heart Lung Transplant 1997; 16: 832-838.

23. Kesten S, Maidenberg A, Winton T, Maurer J. Treatment of presumed and proven acute rejection following six months of lung transplant survival. Am J Respir Crit Care Med 1995; 152: 1321-1324.

24. Swanson SJ, Mentzer SJ, Reilly JJ, et al. Surveillance transbronchial lung biopsies: implication for survival after lung transplantation. J Thorac Cardiovasc Surg 2000; 119: 27-37.

25. Lau CL, Palmer SM, Posther KE, et al. Influence of panelreactive antibodies on posttransplant outcomes in lung transplant recipients. Ann Thorac Surg 2000; 69: 15201524.

26. Slebos DJ, Scholma J, Boezen HM, et al. Longitudinal profile of bronchoalveolar lavage cell characteristics in patients with a good outcome after lung transplantation. Am J Respir Crit Care Med 2002; 165: 501-507.

27. Taylor PM, Rose M, Yacoub M. Expression of MHC antigens in normal human lungs and transplanted lungs with obliterative bronchiolitis. Transplantation 1989; 48: 506-510.

28. Milne DS, Gascoigne AD, Wilkes J, et al. MHC class II and ICAM-1 expression and lymphocyte subsets in transbronchial biopsies from lung transplant recipients. Transplantation 1994; 57: 1762-1766.

29. Milne DS, Gascoigne A, Wilkes J, et al. The immunohistopathology of obliterative bronchiolitis following lung transplantation. Transplantation 1992; 54: 748-750.

30. Devouassoux G, Pison C, Drouet C, Pin I, Brambilla C, Brambilla E. Early lung leukocyte infiltration, HLA and adhesion molecule expression predict chronic rejection Transplant Immunol 2001; 8: 229-236.

31. Jaramillo A, Smith MA, Phelan D, et al. Development of ELISA-detected anti-HLA antibodies precedes the development of bronchiolitis obliterans syndrome and correlates with progressive decline in pulmonary function after lung transplantation. Transplantation 1999; 67: 1155-1156.

32. Palmer SM, Davis RD, Hadjiliadis D, et al. Development of an antibody specific to major histocompatibility antigens detectable by flow cytometry after lung transplant is associated with bronchiolitis obliterans syndrome. Transplantation 2002; 74: 799-804.

33. Rabinowich H, Zeevi A, Paradis IL, et al. Proliferative responses of bronchoalveolar lavage lymphocytes from heartlung transplant patients. Transplantation 1990; 49: 115-121.

34. SivaSai KSR, Smith MA, Poindexter NJ, et al. Indirect recognition of donor HLA Class I peptides in lung transplant recipients with bronchiolitis obliterans syndrome. Transplantation 1999; 67: 1094-1098.

35. Schulman LL, Weinberg AD, McGregor CC, Suciu-Foca NM, Itescu S. Influence of donor and recipient HLA locus mismatching on development of obliterative bronchiolitis after lung transplantation. Am J Respir Crit Care Med 2001; 163: 437-442.

36. Quantz MA, Bennett LE, Meyer DM, Novick RJ. Does human leukocyte antigen matching influence the outcome of lung transplantation? An analysis of 3549 lung transplantations. J Heart Lung Transplant 2000; 19: 473-479.

37. McSherry C, Jackson A, Hertz MI, Bolman III RM, Savik K, Reinsmoen NL. Sequential measurement of peripheral blood allogeneic microchimerism levels and association with pulmonary function. Transplantation 1996; 62: 1811-1818.

38. Duquesnoy R, Zeevi A. Immunological monitoring of lung transplant patients by bronchoalveolar analysis. Transplant Rev 1992; 6: 218-230.

39. De Haan A, van der Gun I, Hepkema BG, et al. Decreased donor-specific cytotoxic $\mathrm{T}$ cell precursor frequencies one year after clinical lung transplantation do not reflect transplantation tolerance: a comparison of lung transplant recipients with or without bronchiolitis obliterans syndrome. Transplantation 2000; 69: 1434-1439.

40. Pham SM, Rao AS, Zeevi A, et al. Effects of donor bone marrow infusion in clinical lung transplantation. Ann Thorac Surg 2000; 69: 345-350.

41. Chaparro C, Maurer JR, Chamberlain D, et al. Causes of death in lung transplant recipients. J Heart Lung Transplant 1994; 13: 758-766.

42. Cahill BC, Hibbs JR, Savik K, et al. Aspergillus airway colonization and invasive disease after lung transplantation. Chest 1997; 112: 1160-1164.

43. Grossi P, Farina C, Fiocchi R, Dalla Gasperina D Prevalence and outcome of invasive fungal infections in 1,963 thoracic organ transplant recipients: a multicenter retrospective study. Italian Study Group of Fungal Infections in Thoracic Organ Transplant Recipients. Transplantation 2000; 70: 112-116.

44. Zamora MR. Controversies in lung transplantation: management of cytomegalovirus infections. J Heart Lung Transplant 2002; 21: 841-849.

45. Speich R, Thurnheer R, Gaspert A, Weder W, Boehler A. Efficacy and cost effectiveness of oral ganciclovir in the prevention of cytomegalovirus disease after lung transplantation. Transplantation 1999; 67: 315-320.

46. Duncan SR, Grgurich WF, Iacono AT, et al. A comparison of ganciclovir and acyclovir to prevent cytomegalovirus after lung transplantation. Am J Respir Crit Care Med 1994; 150: $146-152$.

47. Soghikian MV, Valentine VG, Berry GJ, Patel HR, Robbins $\mathrm{RC}$, Theodore J. Impact of ganciclovir prophylaxis on heartlung and lung transplant recipients. J Heart Lung Transplant 1996; 15: 881-887.

48. Billings JL, Hertz MI, Wendt $\mathrm{CH}$. Community respiratory 
virus infections following lung transplantation. Transpl Infect Dis 2001; 3: 138-148.

49. Vilchez RA, McCurry K, Dauber J, et al. The epidemiology of parainfluenza virus infection in lung transplant recipients. Clin Infect Dis 2001; 33: 2004-2008.

50. Norgaard MA, Andersen CB, Pettersson G. Does bronchial artery revascularization influence results concerning bronchiolitis obliterans syndrome and/or obliterative bronchiolitis after lung transplantation. Eur J Cardiothorac Surg 1998; 14: $311-318$.

51. Novick RJ, Bennett LE, Meyer DM, Hosenpud JD. Influence of graft ischemic time and donor age on survival after lung transplantation. J Heart Lung Transplant 1999; 18: 425-431.

52. Hadjiliadis D, Davis RD, Lawrence CM, et al. Association of bronchiolitis obliterans syndrome (BOS) with gastroesophageal reflux disease (GERD) in lung transplant recipients. Am J Respir Crit Care Med 2001; 163: A325.

53. Palmer SM, Hadjiliadis D, Eubanks WS, et al. Impact of early fundoplication surgery on pulmonary function in lung transplant recipients with gastroesophageal reflux. $\mathrm{Am}$ J Respir Crit Care Med 2001; 163: A325.

54. Lau CL, Palmer SM, Hadjiliadis D, Pappas TN, Eubanks WS, Davis RD. Anti-reflux surgery improves pulmonary function in lung transplant patients. J Heart Lung Transplant 2002; 21: 108

55. Friedman A. Strategies to improve outcomes after renal transplantation. N Engl J Med 2002; 346: 2089-2092.

56. Chisholm MA, Vollenweider LJ, Mulloy LL, et al. Renal transplant patient compliance with free immunosuppressive medications. Transplantation 2000; 70: 1240-1244.

57. Awad M, Pravica V, Perrey C, et al. CA repeat allele polymorphism in the first intron of the human interferongamma gene is associated with lung allograft fibrosis. Hum Immunol 1999; 60: 343-346.

58. El-Gamel A, Awad MR, Hasleton PS, et al. Transforming growth factor-beta (TGF-beta1) genotype and lung allograft fibrosis. J Heart Lung Transplant 1999; 18: 517-523.

59. Yousem SA, Berry GJ, Cagle PT, et al. Revision of the 1990 working formulation for the classification of pulmonary allograft rejection: Lung rejection study group. $J$ Heart Lung Transplant 1996; 15: 1-15.

60. Halloran PF, Homik J, Goes N, et al. The "injury response": a concept linking nonspecific injury, acute rejection, and long-term transplant outcomes. Transplant Proc 1997; 29: 79-81.

61. Marck KW, Wildevuur CR. Lung transplantation in the rat: I. Technique and survival. Ann Thorac Surg 1982; 34: 74-80.

62. Al-Dossari GA, Kshettry VR, Jessurun J, Bolman RM 3rd. Experimental large-animal model of obliterative bronchiolitis after lung transplantation. Ann Thorac Surg 1994; 58: 3440 .

63. Yasufuku K, Heidler KM, Woods KA, et al. Prevention of bronchiolitis obliterans in rat lung allografts by type $\mathrm{V}$ collagen-induced oral tolerance. Transplantation 2002; 73: $500-505$.

64. Hirt SW, You XM, Moller F, et al. Development of obliterative bronchiolitis after allogeneic rat lung transplantation: implication of acute rejection and the time point of treatment. J Heart Lung Transplant 1999; 18: 542-548.

65. Hertz MI, Jessurun J, King MB, Savik SK, Murray JJ. Reproduction of the obliterative bronchiolitis lesion after heterotopic transplantation of mouse airways. Am J Pathol 1993; 142: 1945-1951.

66. Davreux CJ, Chu NH, Waddell TK, Mayer E, Patterson GA. Improved tracheal allograft viability in immunosuppressed rats. Ann Thorac Surg 1993; 55: 131-134.

67. Huang XH, Reichenspurner H, Shorthouse R, Cao W, Berry G, Morris R. Heterotopic tracheal allograft transplantation: a new model to study the molecular events causing obliterative airway disease in rats. J Heart Lung Transplant 1995; 14: S49.
68. Hele DJ, Yacoub MH, Belvisi MG. The heterotopic tracheal allograft as an animal model of obliterative bronchiolitis. Respir Res 2001; 2: 169-183.

69. Boehler A, Chamberlain D, Kesten S, Slutsky AS, Liu M, Keshavjee S. Lymphocytic airway infiltration as a precursor to fibrous obliteration in a rat model of bronchiolitis obliterans. Transplantation 1997; 64: 311-317.

70. Adams BF, Brazelton T, Berry GJ, Morris RE. The role of respiratory epithelium in a rat model of obliterative airway disease. Transplantation 2000; 69: 661-664.

71. Adams BF, Brazelton T, Lange E, Huang X, Morris RE. Airway epithelial cells prevent obliterative airway disease (OAD) in heterotopically transplanted rat tracheal grafts. J Heart Lung Transplant 1998; 17: 47.

72. Rumbley CA, Silver SJ, Phillips SM. Dependence of murine obstructive airway disease on CD40 ligand. Transplantation 2001; 72: 1616-1625.

73. Neuringer I, Mannon RB, Coffman TM, et al. Immune cells in a mouse airway model of obliterative bronchiolitis. Am J Respir Cell Mol Biol 1998; 19: 379-386.

74. Belperio JA, Keane MP, Burdick MD, et al. Critical role for CXCR3 chemokine biology in the pathogenesis of bronchiolitis obliterans syndrome. J Immunol 2002; 169: 1037-1049.

75. Szeto WY, Krasinskas AM, Kreisel D, Popma SH, Rosengard BR. Donor antigen-presenting cells are important in the development of obliterative airway disease. $J$ Thorac Cardiovasc Surg 2000; 120: 1070-1077.

76. Smith MA, Jaramillo A, Sivasai KSR, et al. Indirect recognition and antibody production against a single mismatched HLA-A2-transgenic molecule precede the development of obliterative airway disease in murine heterotopic tracheal allografts. Transplantation 2002; 73: 186-193.

77. Tikkanen JM, Lemström KB, Koskinen PK. Blockade of CD28/B7-2 costimulation inhibits experimental obliterative bronchiolitis in rat tracheal allografts: suppression of helper T cell type1-dominated immune response. Am J Respir Crit Care Med 2002; 165: 724-729.

78. Konishi K, Inobe M, Yamada A, Murakami M, Todo S, Uede T. Combination treatment with FTY720 and CTLA4IgG preserves the respiratory epithelium and prevents obliterative disease in a murine airway model. $J$ Heart Lung Transplant 2002; 21: 692-700.

79. Neuringer IP, Walsh SP, Mannon RB, Gabriel S, Aris RM. Enhanced T cell cytokine gene expression in mouse airway obliterative bronchiolitis. Transplantation 2000; 69: 399405.

80. Boehler A, Bai XH, Liu M, et al. Upregulation of T-helper 1 cytokines and chemokine expression in post-transplant airway obliteration. Am J Respir Crit Care Med 1999; 159: 1910-1917.

81. Suga M, Maclean AA, Keshavjee S, Fischer S, Moreira JM, Liu M. RANTES plays an important role in the evolution of allograft transplant-induced fibrous airway obliteration. Am J Respir Crit Care Med 2000; 162: 1940-1948.

82. Belperio JA, Keane MP, Burdick MD, et al. Critical role for the chemokine MCP-1/CCR2 in the pathogenesis of bronchiolitis obliterans syndrome. J Clin Invest 2001; 108: 547-556.

83. Alho HS, Inkinen KA, Salminen U-S, et al. Collagens I and III in a porcine bronchial model of obliterative bronchiolitis. Am J Respir Crit Care Med 2001; 164: 1519-1525.

84. Aris RM, Walsh S, Chalermskulrat W, Hathwar V, Neuringer IP. Growth factor upregulation during obliterative bronchiolitis in the mouse model. Am J Respir Crit Care Med 2002; 166: 417-422.

85. Tikkanen JM, Kallio EA, Bruggeman CA, Koskinen PK, Lemstrom KB. Prevention of cytomegalovirus infectionenhanced experimental obliterative bronchiolitis by antiviral prophylaxis or immunosuppression in rat tracheal allografts. Am J Respir Crit Care Med 2001; 164: 672-679.

86. Boehler A, Chamberlain D, Xing Z, et al. Adenoviralmediated IL-10 gene transfer inhibits post-transplant fibrous airway obliteration in an animal model of bronchiolitis obliterans. Hum Gene Ther 1998; 9: 541-551. 
87. Roth-Eichhorn S, Schade I, Kasper M, et al. Antiproliferative properties of the phosphodiesterase-4 inhibitor rolipram can supplement immunosuppressive effects of cyclosporine for treatment of obliterative bronchiolitis in heterotopic rat allografts. J Heart Lung Transplant 2001; 20: $1188-1198$.

88. Fahrni JA, Berry GJ, Morris RE, Rosen GD. Rapamycin inhibits development of obliterative airway disease in a murine heterotopic airway transplant model. Transplantation 1997; 63: 533-537.

89. Koskinen PK, Kallio EA, Krebs R, Lemstrom KB. A dosedependent inhibitory effect of cyclosporine A on obliterative bronchiolitis of rat tracheal allografts. Am J Respir Crit Care Med 1997; 155: 303-312.

90. Morris RE, Huang X, Gregory CR, et al. Studies in experimental models of chronic rejection: Use of rapamycin (Sirolimus) and isoxazole derivatives (Leflunomide and its analogue) for the suppression of graft vascular disease and obliterative bronchiolitis. Transplant Proc 1995; 27: 2068-2069.

91. Maclean AA, Liu M, Fischer S, Suga M, Keshavjee S. Targeting the angiotensin system in posttransplant airway obliteration: the antifibrotic effect of angiotensin converting enzyme inhibition. Am J Respir Crit Care Med 2000; 162: $310-315$

92. Kallio EA, Lemström KB, Häyry PJ, Ryan US, Koskinen PK. Blockade of complement inhibits obliterative bronchiolitis in rat tracheal allografts. Am J Respir Crit Care Med 2000; 161: 1332-1339.

93. Reznik SI, Jaramillo A, Zhang L, Patterson GA, Cooper JD, Mohanakumar T. Anti-HLA antibody binding to HLA class I molecules induces proliferation of airway epithelial cells: a potential mechanism for bronchiolitis obliterans syndrome. J Thorac Cardiovasc Surg 2000; 119: 39-45.

94. Jaramillo A, Naziruddin B, Zhang L, et al. Activation of human airway epithelial cells by non-HLA antibodies developed after lung transplantation: a potential etiological factor for bronchiolitis obliterans syndrome. Transplantation 2001; 71: 966-976.

95. Elssner A, Jaumann F, Wolf W-P, et al. Bronchial epithelial cell B7-1 and B7-2 mRNA expression after lung transplantation: a role in allograft rejection. Eur Respir $J$ 2002; 20: $165-169$.

96. Nord M, Schubert K, Cassel TN, Andersson O, Riise GC. Decreased serum and bronchoalveolar lavage levels of clara cell secretory protein $(\mathrm{CC} 16)$ is associated with bronchiolitis obliterans syndrome and airway neutrophilia in lung transplant recipients. Transplantation 2002; 73: 1264-1269.

97. Leonard CT, Soccal PM, Singer L, et al. Dendritic cells and macrophages in lung allografts: a role in chronic rejection. Am J Respir Crit Care Med 2000; 161: 1349-1354.

98. Yousem SA, Ray L, Paradis IL, Dauber JA, Griffith BP. Potential role of dendritic cells in bronchiolitis obliterans in heart-lung transplantation. Ann Thorac Surg 1990; 49: $424-428$.

99. Scholma J, Slebos D-J, Boezen HM, et al. Eosinophilic granulocytes and interleukin-6 level in bronchoalveolar lavage fluid are associated with the development of obliterative bronchiolitis after lung transplantation. $\mathrm{Am}$ J Respir Crit Care Med 2000; 162: 2221-2225.

100. Reynaud-Gaubert M, Thomas P, Badier M, Cau P, Giudicelli R, Fuentes P. Early detection of airway involvement in obliterative bronchiolitis after lung transplantation. Functional and bronchoalveolar lavage cell findings. Am J Respir Crit Care Med 2000; 161: 1924-1929.

101. Zheng L, Walters EH, Ward C, et al. Airway neutrophilia in stable and BOS patients following lung transplantation. Thorax 2000; 55: 53-59.

102. Reynaud-Gaubert M, Marin V, Thirion X, et al. Upregulation of chemokines in bronchoalveolar lavage fluid as a predictive marker of post-transplant airway obliteration. J Heart Lung Transplant 2002; 21: 721-730.
103. Snell GI, Ward C, Wilson JW, Orsida B, Williams TJ, Walters EH. Immunopathological changes in the airways of stable lung transplant recipients. Thorax 1997; 52: 322-328.

104. Ward C, Whitford H, Snell G, et al. Bronchoalveolar lavage macrophage and lymphocyte phenotypes in lung transplant recipients. J Heart Lung Transplant 2001; 20: 1064-1074.

105. Beeh KM, Kornmann O, Lill J, Buhl R. Induced sputum cell profiles in lung transplant recipients with or without chronic rejection: correlation with lung function. Thorax 2001; 56: 557-560.

106. Elssner A, Vogelmeier C. The role of neutrophils in the pathogenesis of obliterative bronchiolitis after lung transplantation. Transpl Infect Dis 2001; 3: 168-176.

107. Riise GC, Andersson BA, Kjellstrom C, et al. Persistent high BAL fluid granulocyte activation marker levels as early indicators of bronchiolitis obliterans after lung transplant Eur Respir J 1999; 14: 1123-1130.

108. Riise GC, Williams A, Kjellstrom C, Schersten H, Andersson BA, Kelly FJ. Bronchiolitis obliterans syndrome in lung transplant recipients is associated with increased neutrophil activity and decreased antioxidant status in the lung. Eur Respir $J$ 1998; 12: 82-88.

109. Hirsch J, Elssner A, Mazur G, et al. Bronchiolitis obliterans syndrome after heart-lung transplantation. Impaired antiprotease defense and increased oxidant activity. Am J Respir Crit Care Med 1999; 160: 1640-1646.

110. Behr J, Maier K, Braun B, Schwaiblmair M, Vogelmeier C. Evidence for oxidative stress in bronchiolitis obliterans syndrome after lung and heart-lung transplantation. Transplantation 2000; 69: 1856-1860.

111. Meyer KC, Nunley DR, Dauber JH, et al. Neutrophils, unopposed neutrophil elastase, and alpha1-antiprotease defenses following human lung transplantation. Am J Respir Crit Care Med 2001; 164: 97-102.

112. Williams A, Riise GC, Anderson BA, Kjellstrom C, Schersten H, Kelly FJ. Compromised antioxidant status and persistent oxidative stress in lung transplant recipients. Free Radic Res 1999; 30: 383-393.

113. Reid D, Snell G, Ward C, et al. Iron overload and nitric oxide-derived oxidative stress following lung transplantation. J Heart Lung Transplant 2001; 20: 840-849.

114. Dai H, Xie C, Churg A. Iron loading makes a nonfibrogenic model air pollutant particle fibrogenic in rat tracheal explants. Am J Respir Cell Mol Biol 2002; 26: 685-693.

115. Elssner A, Jaumann F, Dobmann S, et al. Elevated levels of interleukin-8 and transforming growth factor-beta in bronchoalveolar lavage fluid from patients with bronchiolitis obliterans syndrome: proinflammatory role of bronchial epithelial cells. Transplantation 2000; 70: 362-367.

116. DiGiovine B, Lynch JP III, Martinez FJ, et al. Bronchoalveolar lavage neutrophilia is associated with obliterative bronchiolitis after lung transplantation: role of IL-8. J Immunol 1996; 157: 4194 4202.

117. Charpin J-M, Stern M, Lebrun G, Aubin P, Grenet D, Israel-Biet D. Increased endothelin-1 associated with bacterial infection in lung transplant recipients. Transplantation 2001; 71: 1840-1847.

118. Hertz MI, Henke CA, Nakhleh RE, et al. Obliterative bronchiolitis after lung transplantation: A fibroproliferative disorder associated with platelet-derived growth factor. Proc Natl Acad Sci USA 1992; 89: 10385-10389.

119. Charpin J-M, Stern M, Grenet D, Israel-Biet D. Insulin-like growth factor-1 in lung transplants with obliterative bronchiolitis. Am J Respir Crit Care Med 2000; 161: 1991-1998.

120. El-Gamel A, Sim E, Hasleton $\mathrm{P}$, et al. Transforming growth factor beta (TGF-beta) and obliterative bronchiolitis following pulmonary transplantation. $J$ Heart Lung Transplant 1999; 18: 828-837.

121. Magnan A, Mege JL, Escallier JC, et al. Balance between alveolar macrophage IL-6 and TGF-beta in lung-transplant recipients. Marseille and Montreal Lung Transplantation Group. Am J Respir Crit Care Med 1996; 153: 1431-1436. 
122. Charpin JM, Valcke J, Kettaneh L, Epardeau B, Stern M, Israel-Biet D. Peaks of transforming growth factor-beta mRNA in alveolar cells of lung transplant recipients as an early marker of chronic rejection. Transplantation 1998; 65: 752-755.

123. Jonosono M, Fang KC, Keith FM, et al. Measurement of fibroblast proliferative activity in bronchoalveolar lavage fluid in the analysis of obliterative bronchiolitis among lung transplant recipients. J Heart Lung Transplant 1999; 18: 972-985.

124. Cooper J, Billingham M, Egan $\mathrm{T}$, et al. A working formulation for the standardization of nomenclature and for clinical staging of chronic dysfunction in lung allografts. International Society for Heart and Lung Transplantation. J Heart Lung Transplant 1993; 12: 713-716.

125. Estenne M, van Muylem A, Knoop C, Antoine M. Detection of obliterative bronchiolitis by indexes of ventilation distribution. Am J Respir Crit Care Med 2000; 162: 1047-1051.

126. Ouwens JP, van der Mark TW, Koeter GH, de Boer WJ, Grevink RG, van der Bij W. Bronchiolar airflow impairment after lung transplantation: an early and common manifestation. J Heart Lung Transplant 2002; 21: 1056-1061.

127. Moy ML, Loring SH, Ingenito EP, Mentzer SJ, Reilly JJ Jr. Causes of allograft dysfunction after single lung transplantation for emphysema: extrinsic restriction versus intrinsic obstruction. Brigham and Women's Hospital Lung Transplantation Group. J Heart Lung Transplant 1999; 18: 986-993.

128. Nathan SD, Wolhrab J, Barnett SD. Retrospective validation of BOS $0-p$ as a predictor of BOS in single lung transplant recipients. J Heart Lung Transplant 2002; 21: 76.

129. McGiffin DC. Classification of bronchiolitis obliterans syndrome-taxonomic realism or skepticism. J Heart Lung Transplant 2002; 21: 941-944.

130. Boehler A, Vogt P, Zollinger A, Weder W, Speich R. Prospective study of the value of regular transbronchial lung biopsy in the management of lung transplant recipients. Eur Respir J 1996; 9: 658-662.

131. Trulock EP, Ettinger NA, Brunt EM, Pasque MK, Kaiser LR, Cooper JD. The role of transbronchial lung biopsy in the treatment of lung transplant recipients. An analysis of 200 consecutive procedures. Chest 1992; 102: 1049-1054.

132. Morlion B, Knoop C, Paiva M, Estenne M. Internet-based home monitoring of pulmonary function after lung transplantation. Am J Respir Crit Care Med 2002; 165: 694-697.

133. Finkelstein SM, Snyder M, Stibbe CE, et al. Staging of bronchiolitis obliterans syndrome using home spirometry. Chest 1999; 116: 120-126.

134. van Muylem A, Paiva M, Estenne M. Involvement of peripheral airways during methacholine-induced bronchoconstriction after lung transplantation. Am J Respir Crit Care Med 2001; 164: 1200-1203.

135. Beeh KM, Beier J, Kornmann O, Micke P, Buhl R. Sputum levels of metalloproteinase-9 and tissue inhibitor of metalloproteinase-1, and their ratio correlate with airway obstruction in lung transplant recipients: relation to tumor necrosis factor-alpha and interleukin-10. J Heart Lung Transplant 2001; 20: 1144-1151.

136. Kharitonov SA, Barnes PJ. Exhaled markers of pulmonary disease. Am J Respir Crit Care Med 2001; 163: 1693-1722.

137. Studer SM, Orens JB, Rosas I, et al. Patterns and significance of exhaled-breath biomarkers in lung transplant recipients with acute allograft rejection. J Heart Lung Transplant 2001; 20: 1158-1166.

138. Hofer M, Rechsteiner T, Becher G, et al. Leukotriene B4 in exhaled breath condensate of patients after lung transplantation. Eur Respir J 2001; 18: Suppl. 33, 297s.

139. Gabbay E, Walters EH, Orsida B, et al. Post-lung transplant bronchiolitis obliterans syndrome (BOS) is characterized by increased exhaled nitric oxide levels and epithelial inducible nitric oxide synthase. Am J Respir Crit Care Med 2000; 162: 2182-2187.

140. Silkoff PE, Caramori M, Tremblay L, et al. Exhaled nitric oxide in human lung transplantation. A noninvasive marker of acute rejection. Am J Respir Crit Care Med 1998; 157: $1822-1828$

141. Fisher AJ, Gabbay E, Small T, Doig S, Dark JH, Corris PA. Cross sectional study of exhaled nitric oxide levels following lung transplantation. Thorax 1998; 53: 454458.

142. De Soyza A, Fisher AJ, Small T, Corris PA. Inhaled corticosteroids and the treatment of lymphocytic bronchiolitis following lung transplantation. Am J Respir Crit Care Med 2001; 164: 1209-1212.

143. Bankier AA, Muylem AV, Knoop C, Estenne M, Gevenois PA. Bronchiolitis obliterans syndrome in heart-lung transplant recipients: Diagnosis with expiratory CT. Radiology 2001; 218: 533-539.

144. Lee E-S, Gotway MB, Reddy GP, Golden JA, Keith FM, Webb WR. Early bronchiolitis obliterans following lung transplantation. Radiology 2000; 216: 472-477. 